\title{
Spectrum of biopsied oral and maxillofacial lesions in a tertiary care hospital of Karachi, Pakistan
}

\author{
Syeda H ala Raza', Sufyan Ahmed², M aryam Zafar ${ }^{3}$ \\ 1,3Postgraduate FCPS Resident, D epartment of O ral and M axillofacial Surgery, Karachi M edical \& D ental College \& Abbasi Shaheed H ospital, \\ Karachi, Pakistan. ${ }^{2}$ Associate Professor, Department of O ral and M axillofacial Surgery, Karachi M edical \& D ental College, Abbasi Shaheed \\ H ospital, K arachi, Pakistan. \\ Correspondence to: Dr Syeda H ala Raza, Email: halaraza@gmail.com
}

\begin{abstract}
Objectives: The burden of benign and malignant maxillofacial lesions in developing countries has increased rapidly over the years. O bjective of this study was to provide a spectrum of oral and maxillofacial lesions biopsied in a tertiary care hospital of Karachi, Pakistan and to contribute in baseline data of target population.

Patients and methods: T his descriptive cross sectional study was made of biopsies performed in patients presenting to OPD of Oral and M axillofacial Surgery Department, Abbasi Shaheed H ospital K arachi, Pakistan, between July 2018 till June 2020. A total of 652 patients belonging to either gender, 18-75 years of age, incisional or excisional biopsy were included. Recurrent or previously diagnosed lesions and patients not willing to give informed consent were excluded. D ata including age, gender, site and histopathological diagnosis was recorded on a performa. Descriptive statistical analysis was done using SPSS version 26.

Result: 0 ut of 652 biopsies performed, $(82.9 \%, n=541)$ belonged to soft tissues and $(17.1 \%, n=111)$ were hard tissue lesions. The mean age of patients was 41.82 years, with a male to female ratio of 2.9:1. The most frequent sites biopsied were buccal mucosa $(50.9 \%, n=332)$ and posterior mandible $(10.6 \%, n=69)$. O ral squamous cell carcinoma (OSCC) $(55.1 \%, n=359)$ was the most commonly reported soft tissue lesion with major involved sites buccal mucosa $(74.4 \%, n=267)$, dentoalveolar mucosa $(8 \%, n=29)$ and lateral border of tongue $(7.2 \%, n=26)$ and for hard tissue the most common lesion was ameloblastoma of posterior mandible $(3.5 \%, n=23)$.

Conclusion: This study provides useful information about distribution of oral and maxillofacial lesions and highlights OSCC as the single most frequent diagnosis involving a much younger male population.

Keywords
\end{abstract}

Biopsy, M axillofacial lesions, O ral Squamous C ell C arcinoma, T ertiary care hospital

\section{INTRODUCTION}

A wide variety of lesions can develop in the oral and maxillofacial region, with diverse origins and heterogeneous characteristics, including both benign and malignant lesions. Performing a biopsy is one of the most important investigations in oral surgery. A biopsy shows the morphological characterization of the tissue and is considered to be the gold standard for obtaining a definitive diagnosis for many lesions. ${ }^{1}$ Although oral surgeons are very well versed in diagnosis of oral lesions but at times diagnosing a lesion can be challenging. ${ }^{2}$ Therefore, literature about prevalence of oral and maxillofacial lesions not only increases awareness of disease patterns within populations, but highlights the lesions that are most likely to be encountered in daily practice. W orldwide there have been few histologicalbased studies of oral and maxillofacial lesions that include a comprehensive spectrum both of oral lesions

C onflict of interest: The authors declared no conflict of interest exists.

Citation: Raza SH, Ahmed S, Zafar M. Spectrum of biopsied oral and maxillofacial lesions in a tertiary care hospital of Karachi, Pakistan. J Fatima Jinnah M ed U niv. 2021; 15(2): 81-86.

D OI: https://doi.org/10.37018/M T RK5234 and patients of all ages. ${ }^{3} \mathrm{M}$ ajority of the published articles are designed to analyze only a specific lesion or disease, and limited to a certain age group or based on screenings or clinical surveys, without histological diagnostic confirmation. ${ }^{4-7}$ A 20 -fold global variation in the incidence of these lesions is apparent in international databases. ${ }^{8}$ T wo-thirds of the burden is within the developing world, where underascertainment of cases is significant. ${ }^{9}$ O ne previous study from Karachi reported $75 \%$ of oral and maxillofacial lesions as neoplastic and 25\% nonneoplastic, with granuloma pyogenicum as commonest non neoplastic lesion (37.5\%) and squamous cell carcinoma being commonest malignant neoplastic lesion $(80 \%) .{ }^{10} \mathrm{~T}$ he incidence of Oral Squamous Cell $\mathrm{C}$ arcinoma (OSCC) in $\mathrm{K}$ arachi is the highest reported worldwide. ${ }^{11} \mathrm{~T}$ o enhance the quality of care provided it is also important to develop a pathology database at a single center as well as nation-wide of commonly occurring oral lesions in order to produce skilled and knowledgeable surgeons that can easily provide treatment of lesions considered rare according to international data. T he aim of this study is to determine 
Table 1. Anatomical site distribution of lesions percentages calculated out of a total 652 for both soft and hard tissues

\begin{tabular}{|c|c|c|c|c|}
\hline \multirow[t]{2}{*}{ Anatomical Site of lesion } & \multirow{2}{*}{$\begin{array}{l}\mathrm{N} \text { umber of } \\
\text { cases }(n)\end{array}$} & \multirow[t]{2}{*}{ Percentage (\%) } & \multicolumn{2}{|c|}{ Type of lesion } \\
\hline & & & Benign $(n)$ & M alignant $(n)$ \\
\hline Soft tissue & 541 & 82.9 & 178 & 363 \\
\hline Buccal mucosa & 332 & 50.9 & 63 & 269 \\
\hline $\mathrm{Mn}$ dentoalveolar mucosa & 48 & 7.4 & 32 & 16 \\
\hline $\mathrm{M} \times$ dentoalveolar mucosa & 25 & 3.9 & 12 & 13 \\
\hline Palatal mucosa & 11 & 1.7 & 7 & 4 \\
\hline Retro molar trigone & 20 & 3 & 8 & 12 \\
\hline Tongue & 30 & 4.6 & 1 & 29 \\
\hline Floor of mouth & 5 & .8 & 4 & 1 \\
\hline Lower lip & 38 & 5.8 & 26 & 12 \\
\hline U pper lip & 5 & .8 & 3 & 2 \\
\hline Parotid gland & 10 & 1.6 & 7 & 3 \\
\hline Submandibular gland & 4 & .7 & 3 & 1 \\
\hline M inor glands (palatal mucosa) & 1 & .2 & 0 & 1 \\
\hline Cheek & 11 & 1.7 & 11 & 0 \\
\hline Forehead & 1 & .2 & 1 & 0 \\
\hline $\mathrm{H}$ ard tissue & 111 & 17.1 & 110 & 1 \\
\hline Anterior mandible & 14 & 2.2 & 14 & 0 \\
\hline Posterior mandible & 69 & 10.6 & 68 & 1 \\
\hline Anterior maxilla & 18 & 2.8 & 18 & 0 \\
\hline Posterior maxilla & 10 & 1.5 & 10 & 0 \\
\hline T otal & 652 & 100 & 288 & 364 \\
\hline
\end{tabular}

the frequency of biopsied oral and maxillofacial lesions, in population of a tertiary care hospital of Karachi Pakistan. The study will provide an important baseline data helpful in further management of lesions and for teaching purposes regarding the distribution of histologically diagnosed oral and maxillofacial lesions in target population.

\section{PATIENTS AND METHODS}

T his descriptive cross-sectional study was carried out in a prospective manner for biopsies performed in patients presenting to Department of O ral and Maxillofacial Surgery Abbasi Shaheed Hospital / Karachi Medical and D ental College, Karachi Pakistan, between July 2018 till June 2020. During this period a total of 652 biopsies were performed. Inclusion criteria comprised of patients of either gender, aged 18 to 65 years, persistent lesion that cannot be clinically diagnosed, lesions with no identifiable cause that persist for more than 14 days despite local therapy and any lesion felt to have premalignant or malignant potential. Previously diagnosed or recurrent lesions and patients not willing to give informed consent were excluded from the study. Anterior maxilla is the part of maxilla extending from central incisor to canine region. Posterior Maxilla is part of maxilla extending from first premolar to maxillary tuberosity. Anterior mandible is the part of mandible extending from central incisor to canine region and posterior mandible is the part of mandible extending from first premolar upto condyle and coronoid process. Approval of the institutional ethical review committee was obtained. Incisional or excisional biopsy of the lesions under local or general anesthesia were performed by consultants and post graduate trainees for patients presenting at the Outpatient Department of O ral \& M axillofacial Surgery, Abbasi Shaheed Hospital / Karachi Medical and Dental College $\mathrm{K}$ arachi. T he main presenting complaints were pain, swelling, ulcer, nodular growth and mobility of teeth. Informed consent was taken from each patient. Postoperatively patients were either admitted to ward or observed in OPD. Excised specimens were stored in biopsy bottle with $10 \%$ formalin and sent to laboratory with detailed history sheet for histopathological examination. Data including age, gender, anatomical site and histopathological diagnosis were recorded on a Performa. The descriptive statistical analysis of data obtained was performed to calculate frequency, percentages, means and cross tabulation between variables using SPSS version 26 . The clinicpathological parameters i.e. histopathological diagnoses and anatomical site were compared for both genders using $C$ hi square test. A $p$-value $\varangle 0.05$ was considered as statistically significant.

\section{RESULTS}

A total of 652 biopsies were performed. The mean age of patients was 41.8 years \pm 15.7 , (range $18-75$ years). In this study there was a marked male predominance $(74.2 \%, n=484)$ versus female $(25.8 \%, n=168)$. T he male to female ratio was 2.9:1.T otal $(82.9 \%, n=541)$ of the biopsies corresponded to soft tissues whereas (17.1\%, $\mathrm{n}=111$ ) were from hard tissues. The most 
Table 2. D istribution of soft tissue lesions according to number, percentage, age, gender and predominant site

\begin{tabular}{|c|c|c|c|c|c|c|}
\hline \multirow{2}{*}{ D iagnosis } & \multirow{2}{*}{$n(\%)$} & \multirow{2}{*}{ Age range } & \multirow{2}{*}{ M ean age \pm SD } & \multicolumn{2}{|c|}{ G ender } & \multirow{2}{*}{ Predominant site } \\
\hline & & & & Female & Male & \\
\hline \multicolumn{7}{|l|}{ M alignant } \\
\hline OSCC & $359(55.1)$ & $23-75$ & $46.62 \pm 12.80$ & 74 & 285 & Buccal M ucosa \\
\hline M ucoepidermoid C arcinoma & $4(0.6)$ & $20-57$ & $42.75 \pm 16.87$ & 1 & 3 & Parotid gland \\
\hline Acinic C ell T umor & $1(0.2)$ & 70 & 70 & 0 & 1 & Parotid gland \\
\hline B cell Lymphoma & $1(0.2)$ & 50 & 50 & 0 & 1 & Buccal M ucosa \\
\hline Synovial Sarcoma & $1(0.2)$ & 21 & 21 & 1 & 0 & Buccal M ucosa \\
\hline \multicolumn{7}{|l|}{ Benign/ R eactive } \\
\hline L obular C apillary H emangioma & $25(3.8)$ & $18-75$ & $34.88 \pm 18.04$ & 10 & 15 & Dentoalveolar mucosa \\
\hline Fibroepithelial Polyp/ Fibroma/ & & & & & & Buccal M ucosa, \\
\hline Epulis/ Peripheral O ssifying Fibroma & $22(3.4)$ & $18-51$ & $32.05 \pm 10.91$ & 9 & 13 & D entoalveolar mucosa \\
\hline Squamous Papilloma & $9(1.4)$ & $30-68$ & & 1 & 8 & Buccal M ucosa \\
\hline $\mathrm{H}$ yperplastic $\mathrm{C}$ andidiasis & $9(1.4)$ & $32-75$ & $60.44 \pm 13.50$ & 1 & 8 & Buccal M ucosa \\
\hline Lipoma & $7(1.1)$ & $23-72$ & $45.57 \pm 20.21$ & 2 & 5 & Buccal M ucosa, Cheek \\
\hline Gingival $\mathrm{H}$ yperplasia & $7(1.1)$ & $19-75$ & $37.14+19.77$ & 2 & 5 & Dentoalveolar mucosa \\
\hline Aphthous U Icer & $5(0.7)$ & $32-62$ & $49.20 \pm 11.17$ & 1 & 4 & Buccal M ucosa \\
\hline D ermoid Cyst & $4(0.6)$ & $23-42$ & $31 \pm 8.21$ & 0 & 4 & Cheek \\
\hline Giant C ell granuloma & $3(0.5)$ & $21-40$ & $32.67 \pm 10.21$ & 1 & 2 & D entoalveolar mucosa \\
\hline Sebacceous Cyst & $3(0.5)$ & $26-52$ & $39.67 \pm 13.05$ & 2 & 1 & Cheek \\
\hline E pidermal inclusion cyst & $1(0.2)$ & 19 & 19 & 0 & 1 & Buccal M ucosa \\
\hline Pilomatricoma & $1(0.2)$ & 20 & 20 & 0 & 1 & Buccal M ucosa \\
\hline C avernous $\mathrm{H}$ emangioma & $1(0.2)$ & 24 & 24 & 0 & 1 & Cheek \\
\hline N ecrotic L ymph node & $1(0.2)$ & 30 & 30 & 0 & 1 & Cheek \\
\hline N euroma & $1(0.2)$ & 60 & 60 & 0 & 1 & Buccal M ucosa \\
\hline M ucocele & $21(3.2)$ & $18-43$ & $23 \pm 6.59$ & 6 & 15 & Lower L ip \\
\hline Pleomorphic Adenoma & $8(1.2)$ & $23-54$ & $34.13 \pm 12.57$ & 2 & 6 & Parotid gland \\
\hline Ranula & $2(0.3)$ & $18-19$ & $18.50 \pm 0.71$ & 1 & 1 & Floor of mouth \\
\hline Sialadenitis & $2(0.3)$ & 42 & 42 & 0 & 2 & Submandibular gland \\
\hline \multicolumn{7}{|l|}{ Premalignant } \\
\hline Verrucous L eukoplakia & $11(1.7)$ & $24-57$ & $37.36 \pm 10.01$ & 7 & 4 & Buccal M ucosa \\
\hline L eukoplakia & $10(1.5)$ & $39-65$ & $54.50 \pm 8.79$ & 1 & 9 & Buccal M ucosa \\
\hline OSF & $9(1.4)$ & $22-62$ & $48.22 \pm 13.88$ & 2 & 7 & Buccal M ucosa \\
\hline Squamoproliferative L esion & $8(1.2)$ & $39-75$ & $61 \pm 14.04$ & 2 & 6 & Buccal M ucosa \\
\hline Lichen Planus & $4(0.6)$ & $30-61$ & $43.75 \pm 15.19$ & 1 & 3 & Buccal M ucosa \\
\hline Erythroplakia & $1(0.2)$ & 63 & 63 & 0 & 1 & Palatal M ucosa \\
\hline T otal & $541(82.9)$ & $18-75$ & $44.37 \pm 14.77$ & 127 & 414 & \\
\hline
\end{tabular}

common anatomical site for soft tissue lesions was buccal mucosa $(50.9 \%, n=332)$, followed by mandibular dentoalveolar mucosa $(7.4 \%, \mathrm{n}=48)$ and lower lip $(5.8 \%$, $\mathrm{n}=38)$. M ost frequent site for hard tissue lesions was posterior mandible $(10.6 \%, \mathrm{n}=69)$ and anterior maxilla $(2.8 \%, \mathrm{n}=18)$ respectively. According to anatomical site the distribution of lesions is shown in T able 1 . T otal $(59.2 \%, n=386)$ were incisional biopsies while $(40.8 \%$, $\mathrm{n}=266$ ) were excisional biopsies. Forty seven different histopathological diagnoses were established.

Most of the soft tissue lesions were malignant $(55.6 \%)$, and the most common was oral squamous cell carcinoma $(55.1 \%, n=359)$. In a total of 359 analyzed lesions of O SCC $(74.4 \%, n=267)$ were OSC C of buccal mucosa, more common on right side $(39.5 \%, n=142)$ other involved sites in decreasing order of frequency include dentoalveolar mucosa $(8 \%, n=29)$, lateral border of tongue $(7.3 \%, n=26)$, retromolar trigone $(3.3 \%$, $n=12)$, lower lip $(3.3 \%, n=12)$, ventral surface of tongue $(0.8 \%, n=3)$, upper lip $(0.5 \%, n=2)$ and floor of the mouth $(0.2 \%, n=1)$. Benign soft tissue lesions accounted for $(27.2 \%, n=183)$, where $(3.8 \%, n=25)$ were lobular capillary hemangioma (pyogenic granuloma) occurring mainly at dentoal veolar mucosa with a gender distribution of male $(2.3 \%, n=15)$ and female $(1.5 \%$, $n=10)$. (3.4\%, $n=22)$ were different types of fibrous hyperplasia, with predominant anatomical site buccal and dentoalveolar mucosa and more frequent in males $(2 \%, n=13)$ than females $(1.4 \%, n=9)$.

Pleomorphic adenoma was most common salivary gland tumor $(1.2 \%, n=8)$ with a male predilection $(0.9 \%$, $n=6)$ as compared to females $(0.3 \%, n=2)$ and most common site was parotid gland. Few rare malignant neoplasms of salivary gland, odontogenic and mesenchymal origin were also observed. T able 2 shows the distribution of all soft tissue lesions.

As regards to the hard tissue lesions $(17.1 \%$, $\mathrm{n}=111$ ) most common were ameloblastoma (3.5\%, $n=23)$, followed by odontogenic keratocyst $(2.6 \%, n=17)$ both occurring in posterior mandible. 0 ther hard tissue lesions and their distribution, according to gender, mean age and predominant location are presented in T able 3. 
Table 3. $\mathrm{D}$ istribution of hard tissue lesions according to number, percentage, age, gender and predominant site

\begin{tabular}{|c|c|c|c|c|c|c|}
\hline Diagnosis & $n(\%)$ & Age range & $M$ ean age $\pm S D$ & \multicolumn{2}{|c|}{ G ender } & Predominant Site \\
\hline & & & & Female & M ale & \\
\hline Ameloblastoma & $23(3.5)$ & $18-40$ & $26.35 \pm 6.64$ & 7 & 16 & Posterior mandible \\
\hline O dontogeic K erato Cyst & $17(2.6)$ & $18-29$ & $21.76 \pm 3.527$ & 4 & 13 & Posterior mandible \\
\hline Radicular Cyst & $15(2.3)$ & $18-50$ & $26.67 \pm 8.191$ & 10 & 5 & Anterior mandible \\
\hline M ucormycosis & $11(1.7)$ & $38-69$ & $60.09 \pm 8.396$ & 0 & 11 & Anterior maxilla \\
\hline U nicystic Ameloblastoma & $9(1.4)$ & $19-35$ & $23.22 \pm 4.94$ & 6 & 3 & Posterior mandible \\
\hline D entigerous $\mathrm{Cyst}$ & $8(1.2)$ & $18-20$ & $18.63 \pm 0.744$ & 2 & 6 & Posterior mandible \\
\hline Giant C ell L esion & $6(0.9)$ & $18-27$ & $22.67 \pm 3.67$ & 1 & 5 & Anterior mandible, Anterior maxilla \\
\hline Ossifying Fibroma & $4(0.6)$ & $18-22$ & $19.50 \pm 1.915$ & 3 & 1 & Posterior mandible \\
\hline Osteomyelitis & $4(0.6$ & $59-68$ & $64.25 \pm 4.113$ & 3 & 1 & Posterior mandible \\
\hline Adenomatoid O dontogenic tumor & $3(0.5)$ & 18 & 18 & 0 & 3 & Anterior maxilla \\
\hline Calcifying O dontogenic Cyst & $3(0.5)$ & $27-50$ & $36 \pm 12.28$ & 1 & 2 & Posterior mandible \\
\hline O steochondroma & $2(0.3)$ & $26-30$ & $28 \pm 2.828$ & 2 & 0 & Posterior mandible \\
\hline Odontoma & $2(0.3)$ & $23-43$ & $33 \pm 14.14$ & 1 & 1 & M axilla \\
\hline Burkitt Lymphoma & $1(0.2)$ & 18 & 18 & 0 & 1 & Posterior mandible \\
\hline O dontogenic G host C ell L esion & $1(0.2)$ & 55 & 55 & 1 & 0 & Anterior mandible \\
\hline Paradental Cyst & $1(0.2)$ & 23 & 23 & 0 & 1 & Posterior mandible \\
\hline Cementoma & $1(0.2)$ & 41 & 41 & 0 & 1 & Posterior mandible \\
\hline T otal & $111(17.1)$ & $18-69$ & $29.61 \pm 14.66$ & 41 & 70 & Posterior mandible \\
\hline
\end{tabular}

The patients were divided into two groups according to gender (i.e. male and female) and stratified for clinicopathological features i.e. anatomical site and histopathological diagnosis. Both of the parameters showed statistical difference when compared with gender $(p \varangle 0.002)$ and $(p \varangle 0.001)$ respectively.

\section{DISCUSSION}

In this study, most patients $23.6 \%$ belonged to $4^{\text {th }}$ decade of life, followed by $5^{\text {th }}$ and $3^{\text {rd }}$ decades of life, which is in line with age distribution seen in other studies of our region. ${ }^{10,11} \mathrm{~T}$ here was ahigher incidence of biopsied lesions in males $(74.2 \%, n=484)$ as compared to females $(25.8 \%, n=168)$.

In this study OSCC forms the predominant type accounting for $55.1 \%$ of all lesions. Total $(40.9 \%$, $\mathrm{n}=267$ ) was OSCC buccal mucosa with the most common subsite right buccal mucosa $(21.7 \%, \mathrm{n}=142)$ as compared to left side $(19.1 \%, n=125)$. OSCC lateral border of tongue $(4 \%, n=26)$ dentoalveolar mucosa $(4.45 \%, n=29)$. O ne previous report supports these results in this region of the world. ${ }^{12}$ In present study maximum number of cases were detected in 31 to 40 years age group and the mean age at diagnosis was 46.6 years. W estern literature and previous studies from Pakistan, report majority of cases age incidence to be $5^{\text {th }}$ decade of life. ${ }^{10,12,16} \mathrm{~T}$ hese findings suggest that with passing years not only the incidence of OSCC is increasing but alarmingly it is affecting a much younger population. In current study male to female ratio for OSCC was $(3.9: 1 ; 79.4 \%$ to $20.6 \%)$, similar to international research and other studies in Pakistan which show male predominance. ${ }^{10,13}$
The most common soft tissue lesions were reactive lesions group, lobular capillary hemangioma (pyogenic granuloma) forming $3.8 \%$ of the biopsied lesions, next comes various types of fibrous hyperplasia $3.4 \%$, all located mainly on dentoalveolar and buccal mucosa. Similar findings were reported in a study by Soyele and coworkers, in which most common lesions were pyogenic granuloma followed by fibrous hyperplasia. ${ }^{14}$ On the contrary, other authors reported that fibroepithelial polyps were the most commonly identified lesions as compared to pyogenic granuloma. ${ }^{1,15,16}$ Regarding mucosal lesions, the frequent types were proliferative verrucous leukoplakia $1.7 \%$ and leukoplakia $1.5 \%$ respectively. L eukoplakia was seen in males over 35 years of age. Previous studies also document leukoplakia to be more prevalent among other premalignant lesions. ${ }^{1,17}$ In this series third most common was squamous papilloma $1.4 \%$. H owever, one study revealed a little different prevalence among mucosal lesions, squamous papilloma was more common as compared to leukoplakia. ${ }^{18}$

$M$ any studies have reported a high incidence of mucous retention cyts. ${ }^{19}$ In this study mucocele represented $3.2 \%$ of the biopsies reviewed. Literature shows pleomorphic adenoma as the commonest benign salivary gland tumor. ${ }^{15}$ In current study there were $1.2 \%$ cases of pleomorphic adenoma, mainly in parotid gland with a male to female ratio of 3:1. M ost patients with pleomorphic adenoma belonged to $3^{\text {rd }}$ decade of life. T hese findings are quite similar to a study by Saleh et al which reported a slight male predilection of benign tumors, also in a younger age group. ${ }^{20} \mathrm{M}$ alignancies of salivary gland in present study included mucoepidermoid carcinoma $0.6 \%$ and acinic cell tumor 
$0.3 \%$. Sialadenitis was $0.3 \%$ only seen in submandibular gland. Among hard tissue lesions $12.8 \%$ were located in mandible, while $4.3 \%$ were present in maxilla. The single most common odontogenic tumor was ameloblastoma, 32 cases in a total of 111 hard tissue lesions, of which $3.5 \%$ were solid multicystic ameloblastoma and $1.4 \%$ were unicystic ameloblastoma. It mostly affected males and was more common in the $3^{\text {rd }}$ decade of life. In contrast a study conducted in Saudia Arabia, showed ameloblastoma to be more common in females. ${ }^{20} \mathrm{~V}$ arious studies from Pakistan, M exico, Japan, Nigeria, and Jordan suggest radicular cyst as the most common jaw cyst followed by dentigerous and $\mathrm{OKC} .{ }^{21} \mathrm{~T}$ his study reports slightly different figures; most frequent representative was odontogenic keratocyst $2.6 \%$ followed by radicular cyst $2.3 \%$ and dentigerous cyst $1.2 \%$. Other odontogenic tumors were rare including odontogenic ghost cell tumor. Another significant observation is the frequency of mucormycosis $(1.7 \%)$, a serious invasive fungal infection in maxilla. Eleven out of 111 hard tissue lesions were diagnosed, this shows increased number of mucormycosis in target population. Similarly, according to a study in recent years there has been a rise globally in incidence of mucormycosis, but in the Asian continent it is reported to be highest. ${ }^{22} 0$ nly 4 cases of osteomyelitis $(0.6 \%)$ with a mean age of 64.25 years and a female to male ratio of $3: 1$ were described in this study. These findings are consistent with studies worldwide. ${ }^{23}$

As this is a single centre study, the data in this study may not represent national epidemiology of oral and maxillofacial lesions. The pathological diagnoses are included from patients who underwent biopsy. Other cases with limited access to standard treatment, who did not undergo biopsy are missing in our study. It was not a very large population based study, but nevertheless it may help in monitoring disease patterns and changing trends. The data from this study may provide information regarding spectrum of common maxillofacial lesions for future research and planning.

\section{CONCLUSION}

This study provides information about distribution of oral and maxillofacial lesions and highlights OSCC as the single most frequent diagnosis involving a much younger male population. This data will be helpful for comparison with other countries.

\section{REFERENCES}

1. M onteiro LS, Albuquerque R, Paiva A, Peña-M oral J, Amaral JB, L opes CA. A comparative analysis of oral and maxillofacial pathology over a 16-year period, in the north of Portugal. Int Dent J. 2017;67(1):38-45.

2. Ergun $S$, Özel $S, K$ oray $M, K$ ürklü $E, A k G, T$ anyeri $H$. Dentists' knowledge and opinions about oral mucosal lesions. Int J O ral M axillofac Surg. 2009;38(12):1283-8.

3. M endez M, Carrard VC, H aas AN, L auxen ID, Barbachan JJ, Rados PV, et al. A 10-year study of specimens submitted to oral pathology laboratory analysis: lesion occurrence and demographic features. Braz Oral Res. 2012;26(3):235-41. 4.Pentenero $M$, Broccoletti $R$, Carbone $M$, Conrotto $D$, $\mathrm{G}$ andolfo $\mathrm{S}$. T he prevalence of oral mucosal lesions in adults from the T urin area. O ral D is. 2008;14(4):356-66.

5. de $V$ asconcelos $C$ arvalho $M$, I glesias DP, do $N$ ascimento $G$ J, Sobral AP. Epidemiological study of 534 biopsies of oral mucosal lesions in elderly Brazilian patients. Gerodontology. 2011;28(2):111-5.

6. Ha WN, Kelloway E, Dost F, Farah CS. A retrospective analysis of oral and maxillofacial pathology in an Australian paediatric population. Aust D ent J. 2014;59(2):221-5.

7. Shafique $\mathrm{S}, \mathrm{H}$ aider $\mathrm{SM}, \mathrm{Ali} \mathrm{Z}$. H istological patterns and clinical presentation of oral squamous cell carcinoma. J Pak Dent Assoc. 2010;19(3):171-6.

8. Ariyawardana A, Johnson N W. T rends of lip, oral cavity and oropharyngeal cancers in Australia 1982-2008: overall good news but with rising rates in the oropharynx. BM C Cancer. 2013;13(1):333.

9. Swaminathan R, Rama R, Shanta V. Lack of active follow-up of cancer patients in Chennai, India: implications for populationbased survival estimates. Bull World Health Organ. 2008 ;86(7):509-15.

10. Bukhari U, Sonia SA, K hooharo Y. H istopathological audit of oral epithelial lesions. Pakistan Oral \& Dental Journal. 2014;34(3):457-61.

11. Bhurgri $Y$, Bhurgri A, Pervez $S$, Bhurgri $M$, Kayani $N$, Ahmed $\mathrm{R}$, et al. Cancer profile of Hyderabad, Pakistan 1998-2002. Asian Pac J Cancer Prev 2005; 6:474-80.

12. Akram S, M irza T, M irza M A, Q ureshi M. Emerging patterns in clinico-pathological spectrum of O ral Cancers. Pak J M ed Sci. 2013;29(3):783-787

13. Badar F, Mahmood S. Epidemiology of cancers in Lahore, Pakistan, among children, adolescents and adults, 2010-2012: a cross-sectional study part 2. BM J O pen. 2017;7(12):1-15.

14. Soyele O O, Ladeji AM, Adebiyi KE, Adesina OM, Aborisade $A O$, et al. Pattern of distribution of reactive localised hyperplasia of the oral cavity in patients at a tertiary health institution in N igeria. Afr H ealth Sci. 2019;19(1):1687-94.

15. U rooj A, M irza T, Agha M A, Rasool S. Frequency of head and neck lesions according to histopathologic diagnosis. J Dow U niv H ealth Sci. 2011;5(2):70-3.

16. Alhindi NA, Sindi AM, Binmadi NO, Elias WY. A retrospective study of oral and maxillofacial pathology lesions diagnosed at the Faculty of Dentistry, King Abdulaziz U niversity. Clin C osmet Investig D ent Clinical. 2019;11:45.

17. Verma S, Sharma H. Prevalence of O ral mucosal lesions and their association with Pattern of tobacco use among patients visiting a dental institution. Indian J D ent Res 2019;30:652-5

18. Tortorici S, Corrao S, N atoli G, D ifalco P. Prevalence and distribution of oral mucosal non-malignant lesions in the western Sicilian population. M inerva Stomatol. 2016;65(4):191-92

19. Fierro $C$, Almendros $M$ arqués $N$, Berini Aytés $L, G$ ay Escoda C. Prevalence of biopsied oral lesions in a $D$ epartment of $O$ ral Surgery (2007-2009). J Clin Exp D ent 2011;3(2):e73-7. 
20. Saleh SM, Idris AM, V ani N V , T ubaigy FM, Alharbi FA, et al. Retrospective analysis of biopsied oral and maxillofacial lesions in South-W estern Saudi Arabia. Saudi M ed J. 2017 ;38(4):405.

21. Awan MU, Babar A, Ibrahim M W . Pattern and presentation of odontogenic jaw cysts: A clinical experience. Pak Armed Forces M ed J. 2017;67(1):102-06.
22. Prakash $\mathrm{H}$, Chakrabarti A. Global epidemiology of mucormycosis. J Fungi (Basel). 2019;5(1):26.

23. Park MS, Eo MY, M young H, Kim SM, Lee JH. Early diagnosis of jaw osteomyelitis by easy digitalized panoramic analysis. M axillofac Plast Reconstr Surg. $2019 ; 41(1): 6$. 